\title{
Studies on newly developed urethane modified polyetheramide coatings from Albizia benth oil
}

\author{
Akintayo Cecilia $\mathrm{O}^{1}$, Akintayo Emmanuel $\mathrm{T}^{{ }^{1 *}}$ and Ziegler Thomas ${ }^{2}$ \\ ${ }^{1}$ Chemistry Department, University of Ado-Ekiti, P.M.B 5363, Ado-Ekiti, Ekiti State, \\ Nigeria \\ ${ }^{2}$ Institute of Organic Chemistry, University of Tubingen, Tubingen, Germany. \\ *Corresponding Author - E mail : temitopeakintayo@yahoo.com \\ Phone: 002348030659661
}

\begin{abstract}
Polyetheramide resin based on the condensation polymerisation of $\mathrm{N}-\mathrm{N}$ bis (2-hydroxyethyl) Albizia benth oil fatty amide with Bisphenol-A was synthesized. The polyetheramide was further modified with urethane linkage resulting from the addition reaction of free hydroxyl groups of the hydroxylethyl Albizia benth oil fatty amide and the isocyanate moeity of toluene 2,4 di-isocyanate. The spectroscopic characterisation (FT-IR, ${ }^{1} \mathrm{H}$ NMR, ${ }^{13} \mathrm{C} N M R$ ) as well as the thermal, physicochemical and coating properties of the polyetheramide and its urethaned modified derivatives were carried out. Urethanation led to curing at lower temperature, increase in glass transition and improvement in coating properties and resistance to chemical corrosion
\end{abstract}

Keywords: Albizia benth oil, polyetheramide, urethanation, coating

\section{Introduction}

The production of vegetable oil based polymeric materials with excelent physical and chemical properties has drawn large attention in recent times [Alam et al. (2004), Ahmad et al. (2005),Shabeer et al. (2005), Li et al. (2000)]. Introduction of hydroxyl groups at the position of double bonds of triglycerides opens the whole area of applications. Castor oil is the only natural source of an 18 carbon hydroxylated fatty acid with one double bond. The functionalities of most other vegetable oil depends largely on the modification carried out at the reactive sites. Reacting oil based diols with suitable monomers for example produces polyetheramides. This polymeric material had been reported to contain carbon carbon and ether linkages which confer good chemical resistance in particular against alkalis along with excellent adhesion and flexibility [Li et al. (2001), Ahmad et al. (2003)] as well as good anticorrosive properties[Alam et al., 2004]. Modification of polyetheramide with urethane will further confer on the final product (urethane modified polyetheramide) an improved thermal stability with good adhesion, excellent abrasion resistance, high toughness and good out door service as well as good water and acid resistance [Aigbodion et al. (2001), Ahmad et al., (2001)].

Literature review reveals very few works reported on newly developed oil based polyetheramide [Alam et al. (2004), Ahmad et al. (2002), Wei et al. (2002)]. The use of underutilized seed oil like Albizia benth oil as a cheap source of supply of renewable resources that may be used for production of enviromentally friendlier resin had been reported earlier [Akintayo and Adebowale, 2004 a,b;]. Albizia benth, a native of tropical Africa, Asia and Northern Australia is a fast growing nitrogen fixing heavy shade tree that is only used for reforestation and firewood. The high yield seed oil ca $40 \%$ is used only for curing leprosy and there is no reported work on the development of Albizia benth oil polyetheramide resin. This work thus seek to study the synthesis of polyetheramide produced by condensation polymerization of $\mathrm{N}-\mathrm{N}$ bis (2 - hydroxyethyl) Albizia benth oil fatty amide [HEABOA] with Bisphenol - A . The product is modified with urethane linkage resulting from the addition reaction of free hydroxyl groups of HEABOA and isocyanate moiety of toluene 2,4 - di isocyanate (TDI). The polyetheramide and its modified derivatives were characterized by FT-IR, ${ }^{1} \mathrm{H}$ NMR and ${ }^{13} \mathrm{C}$ NMR. The physicochemical and film coating properities were also carried out.

\section{EXPERIMENTAL}

Collection of samples: Albizia benth seeds were collected from nearby farms and bushes in Ado-Ekiti, Nigeria. The seeds were milled on a C\&N Junior laboratory mill size 5 (Christy and Norris Limited Engineers, Chemlsford, England). 
Extraction and refining of Oil: Albizia benth oil (ABO) were extracted using $n$-hexane in a Soxhlet apparatus and solvent was removed on a rotavapour. The crude oil were refined by agitating with $18 \mathrm{M}$ $\mathrm{NaOH}(1: 30 \mathrm{~g} / \mathrm{g})$ for $15 \mathrm{~min}$. The resultant mixture was then heated to $75-80^{\circ} \mathrm{C}$ to break the soap stock and neutral oil separated by centrifugation.

Synthesis of Albizia benth oil fatty amide: 0.32 mol of diethanolamine and $0.007 \mathrm{~mol}$ of sodium methoxide were mixed in a four necked round bottom flask fitted with an electrical stirrer, thermometer and condenser and contents heated to $110^{\circ} \mathrm{C}$ while stirring. $A B O(0,1 \mathrm{~mol})$ was then added dropwisely over a period of $60 \mathrm{~min}$. Progress of the reaction was monitored by TLC. On completion the reaction product was dissolved in diethyl ether, washed with $15 \% \mathrm{NaCl}$ and dried over $\mathrm{Na}_{2} \mathrm{SO}_{4}$. The ethereal layer was filtered and evaporated in a vacuum evaporator to obtain the bis(2-hydroxyethyl) Albizia benth oil fatty amide (HEABOA)

Synthesis of Albizia benth Oil Polyetheramide (ABOPEtA): Bis(2-hydroxyethyl) Albizia benth fatty amide (HEABOA) was first prepared as described above. Now $0.10 \mathrm{~mol}$ of $\mathrm{HEABOA}$ and $0.07 \mathrm{~mol}$ bisphenol were dissolved in $100 \mathrm{ml}$ of a mixture of xylene and butanone $(1: 1 \mathrm{v} / \mathrm{v})$ as solvent with dil. $\mathrm{H}_{2} \mathrm{SO}_{4}$ as a catalyst in a four necked round bottom flask equipped with Dean stark, $\mathrm{N}_{2}$ inlet, thermometer and stirrer. The reaction mixture was heated to $180^{\circ} \mathrm{C}$ and allowed to reflux. Progress of reaction was monitored by TLC and hydroxyl value.

Synthesis of Urethanated Albizia benth Oil Polyetheramide (UABOPEtA): Albizia benth Oil Polyetheramide (ABOPEtA) prepared as described above was mixed with toluene 2-4-diisocyanate in the ratios $9: 1 ; 8: 2$; and $7: 3$ wt $\%$ in a mixture of xylene and butanone $(1: 1 \mathrm{v} / \mathrm{v})$ in a four necked flask under $\mathrm{N}_{2}$ atmosphere and continuous stirring and at $120^{\circ} \mathrm{C}$. The reaction was monitored by TLC and hydroxyl value determination.
Characterisation: Samples were characterised by spectroscopic techniques such as FT-IR, ${ }^{1} \mathrm{H}$ NMR and

${ }^{13} \mathrm{C}$ NMR. FTIR spectra were recorded on Tensor 27 FTIR-H1026302 (Bruker Optik, GmBh, Germany) and ${ }^{1} \mathrm{H}$ and ${ }^{13} \mathrm{C}$ - NMR spectra obtained on a Bruker Avance - 400 (Bruker Instruments, Inc. Karlsruhe, Germany) Fourier transform spectrometer operating at $400.6 \mathrm{MHz}$. The gated decoupling pulse sequence was used with the following parameters, number of scans, 256; acquisition time, 1.366s; pulse width $10.3 \mu \mathrm{s}$. Free induction decay FID was transformed and zero filled to $300 \mathrm{~K}$ to give digital resolution of $2 \mathrm{~Hz} /$ point. Thermal analysis was carried out by DSC $822^{\mathrm{e}}$ (Mettler Toledo GmBH, Giessen, Germany). Hydroxyl value (HV), lodine value (IV), saponification value (SV) and refractive index (RI) were determined according to standard procedures (DFG, 1994)

Evaluation of coating characteristics: Samples were thinned in toluene to a brushable consistency. The solutions prepared were applied by brush on clean mild steel panels of $15 \mathrm{~cm} \times 15 \mathrm{~cm}$ for evaluating drying time, tin panels of the size $15 \times 15 \mathrm{~cm}$ for flexibility and adhesion, scratch hardness and impact resistance and glass panels of the size $15 \times 15 \mathrm{~cm}$ for water, alkali and solvent resistance. All coated panels were air dried for $48 \mathrm{hr}$ and sides protected by dipping them into molten wax before carrying out the above tests. The film characteristics were determined according to Indian standard specifications (IS, 1964; IS 1981)

\section{RESULTS AND DISCUSSION}

Schemes 1, 2 and 3 shows the reactions schemes for the synthensis of Hydroxylethyl Albizia benth oil amide [HEABOA] , Albizia benth oil Polyetheramide (ABOPEtA) and Urethaned Albizia benth oil Polyetheramide (UABOPEtA) respectively. 
Am. J. Sci. Ind. Res., 2011, 2(1): 78-88

$\mathrm{CH}_{2} \mathrm{OCOR}$

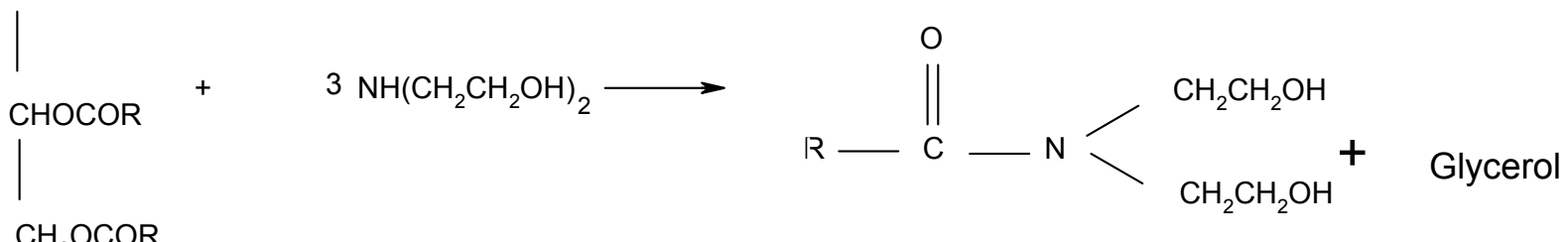

$\mathrm{ABO}$

Diethanolamine

Hydroxylethylalbizia benth oil amide

(HEABOA)

Scheme 1 : Synthesis of HEABOA

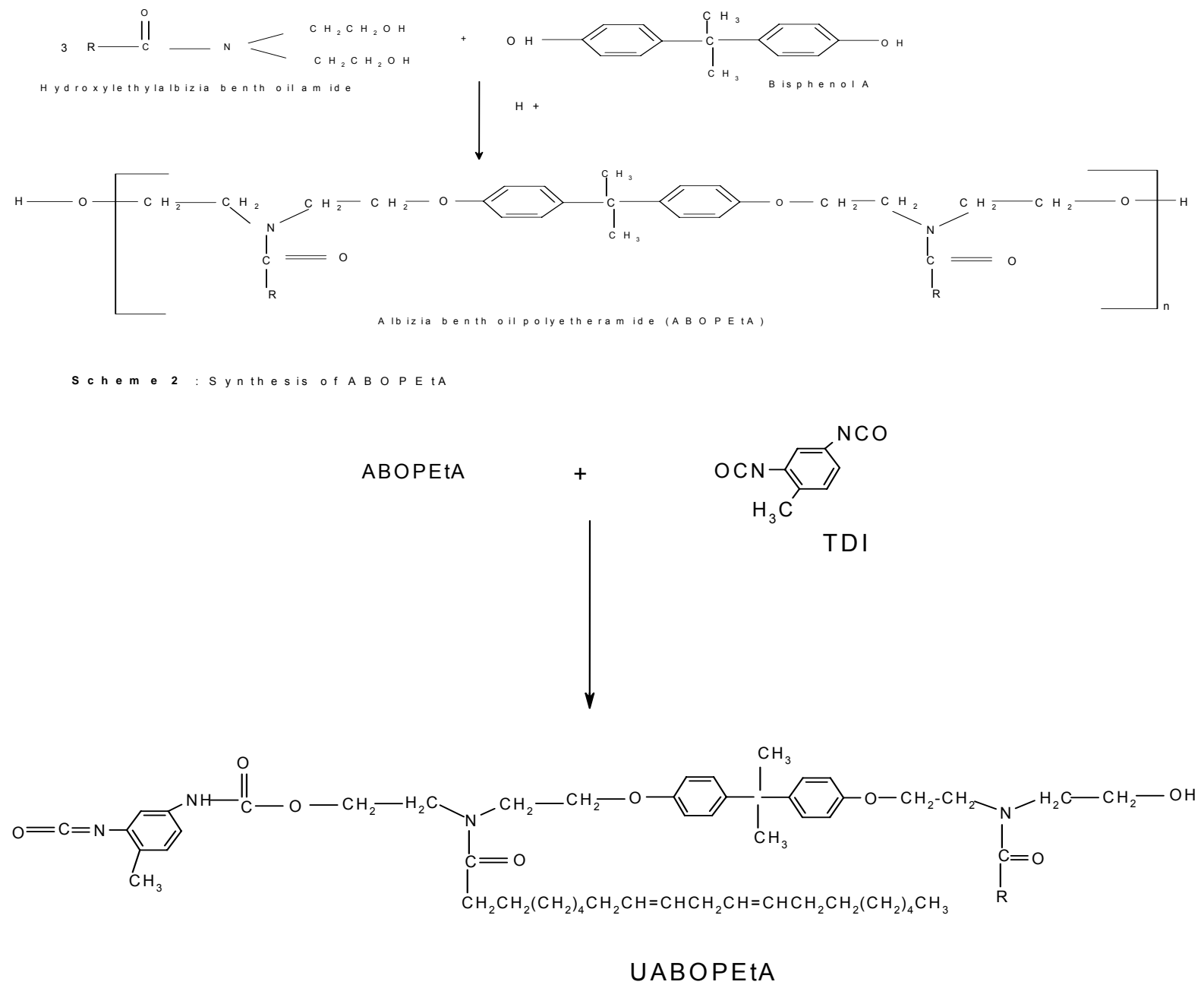

Scheme 3 : Synthesis of UABOPEtA 
The fatty amide were obtained by the reaction of diethnolamine with Albizia benth seed oil. HEABOA obtained was reacted with bisphenol-A to form polyetheramide (ABOPEtA) with free hydroxyl groups. Reactions of the ABOPEtA with toluene 2,4 diisocyanate at ratios $9: 1, \quad 8: 2$ and $7: 3$ yielded different urethane modified polyetheramide resin (UABOPEtA). The structural features of HEABOA, ABOPEtA and UABOPEtA were confirmed using FTIR, ${ }^{1} \mathrm{H}$ NMR and ${ }^{13} \mathrm{C}$ NMR spectral analysis.

Spectral Analysis of HEABOA: Fig. 1 presents the FTIR spectrum of HEABOA. The broad band at 3400 $\mathrm{cm}^{-1}$ showed the characteristic absorption band for alcoholic $\mathrm{OH}$ group. $\mathrm{CH}_{2}$ assymetric and symmetric stretching peaks appear at $2925 \mathrm{~cm}^{-1}$ and $2854 \mathrm{~cm}^{-1}$ respectively. Band at $1621 \mathrm{~cm}^{-1}$ represent the stretching vibration of $\mathrm{C}=\mathrm{O}$ of amide. The $\mathrm{C}-\mathrm{N}$ stretching peak is $1049 \mathrm{~cm}^{-1}$ while the $\mathrm{CH}_{2}$ bending is at $1466 \mathrm{~cm}^{-1}$. The ${ }^{1} \mathrm{H}$ NMR spectrum, Fig 2 of HEABOA shows characteristic peaks at $\delta$ 0.88- 0.9 ppm (terminal $\left.\mathrm{CH}_{3}\right), \delta=2.04-2.06 p p m\left(\mathrm{CH}_{2}-\mathrm{C}=\right)$, $\delta$ $2.37-2.41 \mathrm{ppm}\left(\mathrm{CH}_{2}-\mathrm{C}=\mathrm{N}\right), \delta 1.27 \mathrm{ppm}\left(\mathrm{CH}_{2}\right), \delta$ 2.762.79ppm ( $\left.=\mathrm{CCH}_{2} \mathrm{C}=\right), \quad \quad \mathrm{CH}_{2}$ attached to amide nitrogen is at $\delta 3.46-3.57 \mathrm{ppm}$ while $\mathrm{CH}_{2}-\mathrm{OH}$ occurs at $\delta=3.78-3.84 \mathrm{ppm}$ and alcoholic $\mathrm{OH}$ is at $\delta=5.34$ $-5.38 \mathrm{ppm}$. The ${ }^{13} \mathrm{C}$ presented in Fig 3 further confirms the structure of HEABOA by the presence of the signals at $\delta$ 26-33ppm (various $-\mathrm{CH}_{2}$ ), 50-52ppm $\left(\mathrm{CH}_{2} \mathrm{CO}\right), 66.2 \mathrm{ppm}\left(-\mathrm{CH}_{2} \mathrm{~N}-\right), 128-130 \mathrm{ppm}$ (olefinic protons of fatty amide).

Spectral Analysis of ABOPEtA:The formation of ABOPEtA is supported by the presence of the following characteristic peaks in the infrared spectra as presented in Fig 1; C-O-C for aryl alkyl ether at $1247-1177 \mathrm{~cm}^{-1}$ and $1081 \mathrm{~cm}^{-1}$ for asymmetrical and symmemtrical stretching respectively. The $\mathrm{CH}_{2}$ asymmetrical strecthing band at $2854 \mathrm{~cm}^{-1}$ and symmetrical streching at $2925 \mathrm{~cm}^{-1}$ are charactertistic of $-\mathrm{CH}_{2}$ fatty amide chains. Bands observed at
$3011 \mathrm{~cm}^{-1}$ is for the $-\mathrm{C}-\mathrm{H}$ stretching of unsaturation in the chain. The terminal hydroxyl group is reflected by the broad band at $3308 \mathrm{~cm}^{-1}$ (with reduced intensity when compared to HEOA). $\mathrm{C}=\mathrm{O}$ stretching of amide is observed at $1612 \mathrm{~cm}^{-1}$ while the $-\mathrm{CN}$ - stretching occurs at $1464 \mathrm{~cm}^{-1}$. The absorption bands appearing at $904-743 \mathrm{~cm}^{-1}$ are due to the group vibrational frequencies of $\mathrm{C}-\mathrm{H}$ for both aromatic rings of bisphenol-A and $\left(\mathrm{CH}_{2}\right) \mathrm{n}$ when $\mathrm{n}$ is more than four.

The ${ }^{1} \mathrm{H}$ NMR of ABOPEtA (Fig 4) gives characteristic peaks at $\delta 1.28 \mathrm{ppm}$ and $\delta 6.73-7.17 \mathrm{ppm}$ for gem dimethyl protons and for aromatic ring proton of bisphenol-A respectively. The appearance of peaks at $\delta 4.08-4.2 \mathrm{ppm}$ corresponding to $-\mathrm{CH}_{2}$ linked with -O- aromatic confirms the formation of ether in the reaction of HEOA with bisphenol $\mathrm{A}$. The $-\mathrm{CH}_{3}$ and $\mathrm{CH}_{2}$ for terminal and internal fatty amide chains were conspicously observed at $\delta 0.91$ and $\delta 1.29-1.31 p p m$ respectively. While the $-\mathrm{CH}_{2}$ linked with the olefinic double bond is at $\delta$ 2.03-2.08ppm, characteristic peaks for $-\mathrm{CH}_{2}$ attached to amide nitrogen and that of amide carbonyl were both present at $\delta 3.87$ $3.8 \mathrm{ppm}$ and $\delta 2.4-2.29 \mathrm{ppm}$ respectively. Peaks at $\delta=3.58-3.51$ and $\delta=5.38-5.36 \mathrm{ppm}$ are all characteristic peaks for $\mathrm{CH}_{2}$ attached to the hydroxyl and olefinic protons respectively. The presence of these peaks confirm that the reaction between HEOA with bisphenol-A produced ABOPEtA. The product is further confirmed by ${ }^{13} \mathrm{C}$ NMR (Fig 5) that shows peaks at $\delta 29.5-29.7 \mathrm{ppm}$ of $-\mathrm{CH}_{2}$ and $\delta 42 \mathrm{ppm}$ for quaternary carbon of bisphenol $\mathrm{A}$, while that of aromatic carbon of bisphenol is obsrerved at $\delta=$ $128.5 \mathrm{ppm}$ to $126.5 \mathrm{ppm}$ and $\delta 15.1 \mathrm{ppm}$. The $-\mathrm{CH}_{2}$ peak of HEOA attached to bisphenol A through ethyl linkages is at $\delta=20-61.29 \mathrm{ppm}$. The olefinic carbon of fatty amide chain appear as peak at $\delta 138.1$ 133ppm. 
Am. J. Sci. Ind. Res., 2011, 2(1): 78-88

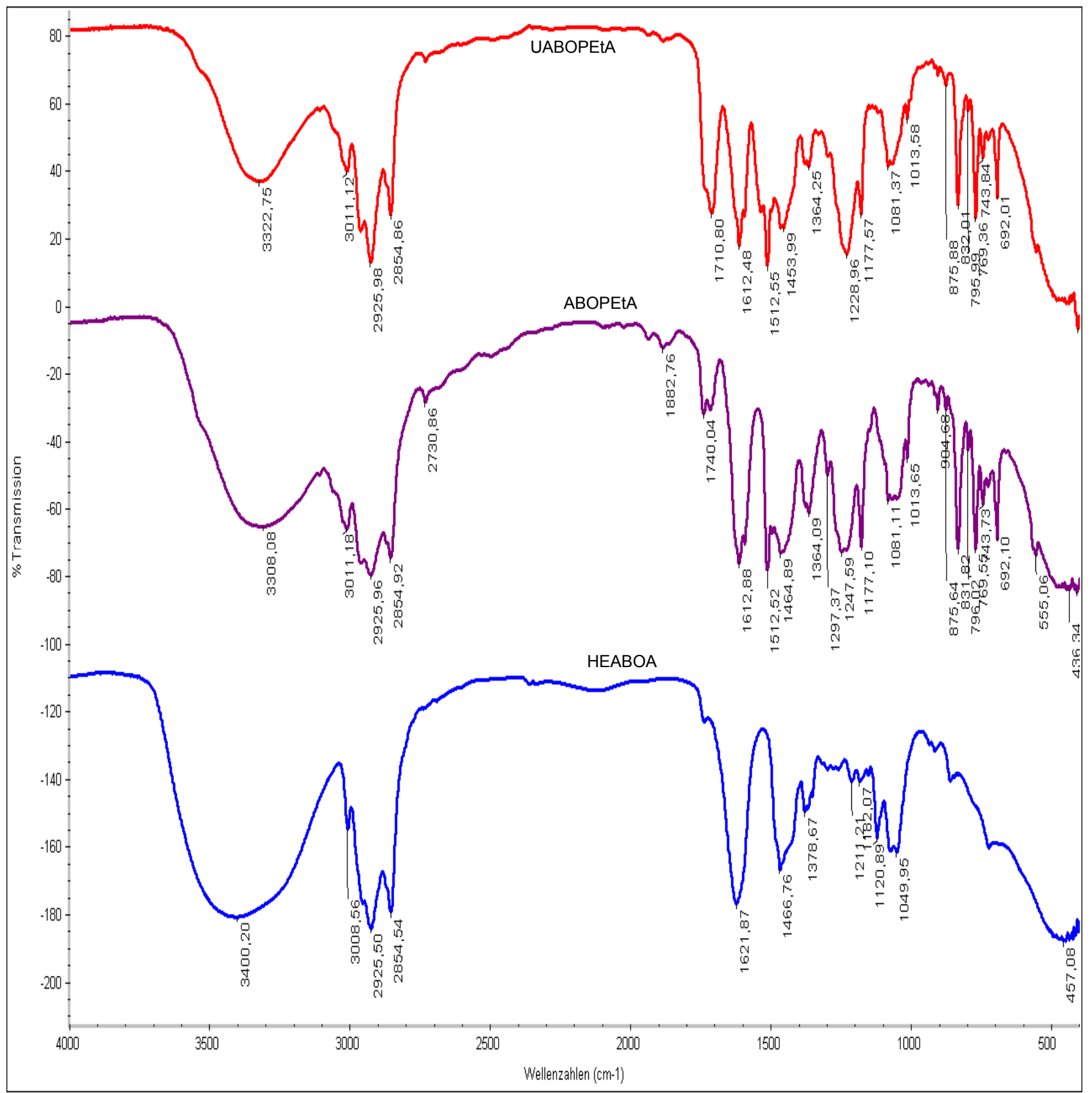

Fig 1:- FT-IR of Albizia benth hydroxyethyl oil amide (HEABOA), Albizia benth oil polyetheramide (ABOPEtA) and urethaned Albizia benth oil polyetheramide (UABOPEtA) and Urethaned Polyetheramide (UABOPEtA) 
Am. J. Sci. Ind. Res., 2011, 2(1): 78-88

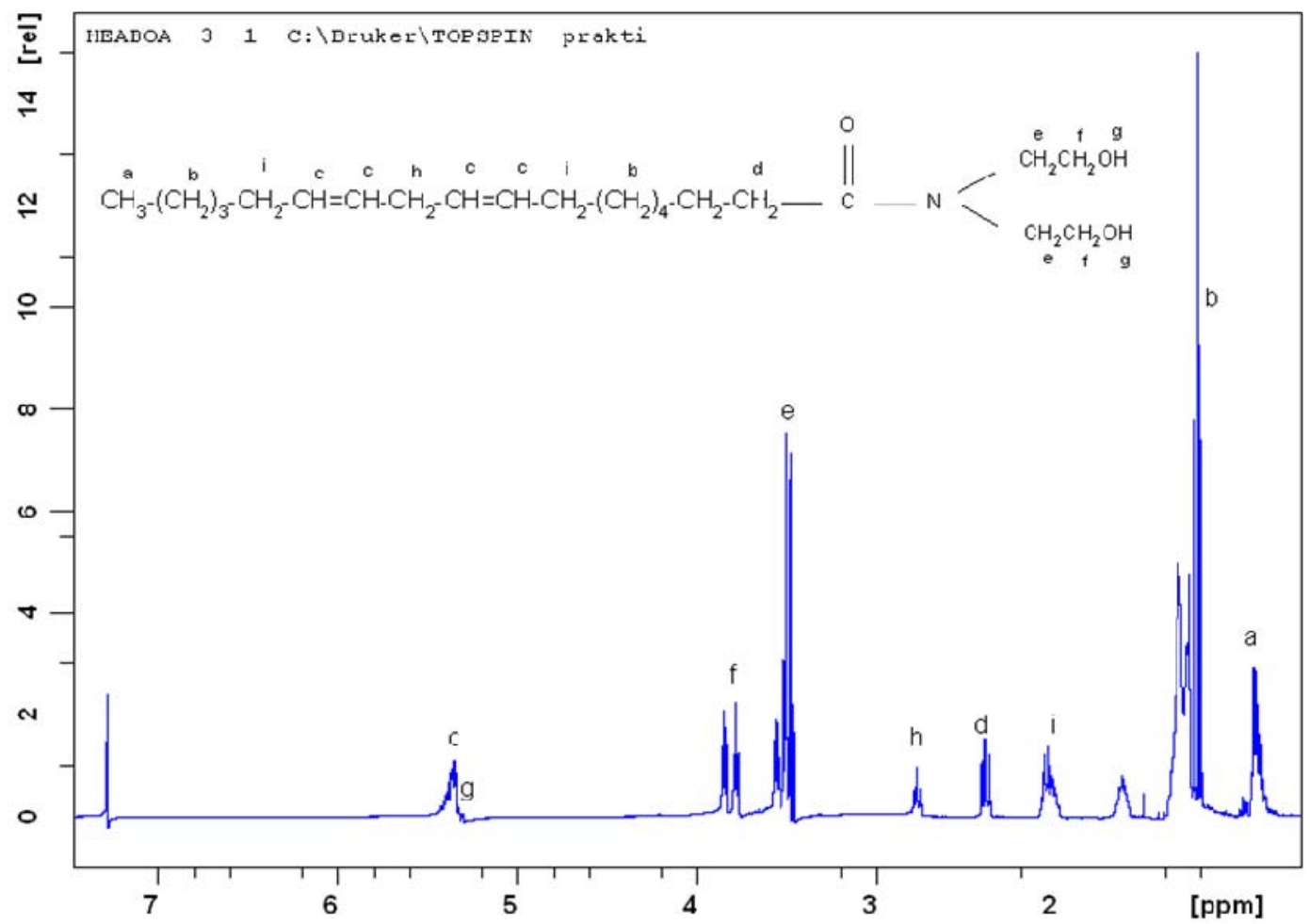

Fig 2: ${ }^{1} \mathrm{H}$ NMR spectra of HEABOA

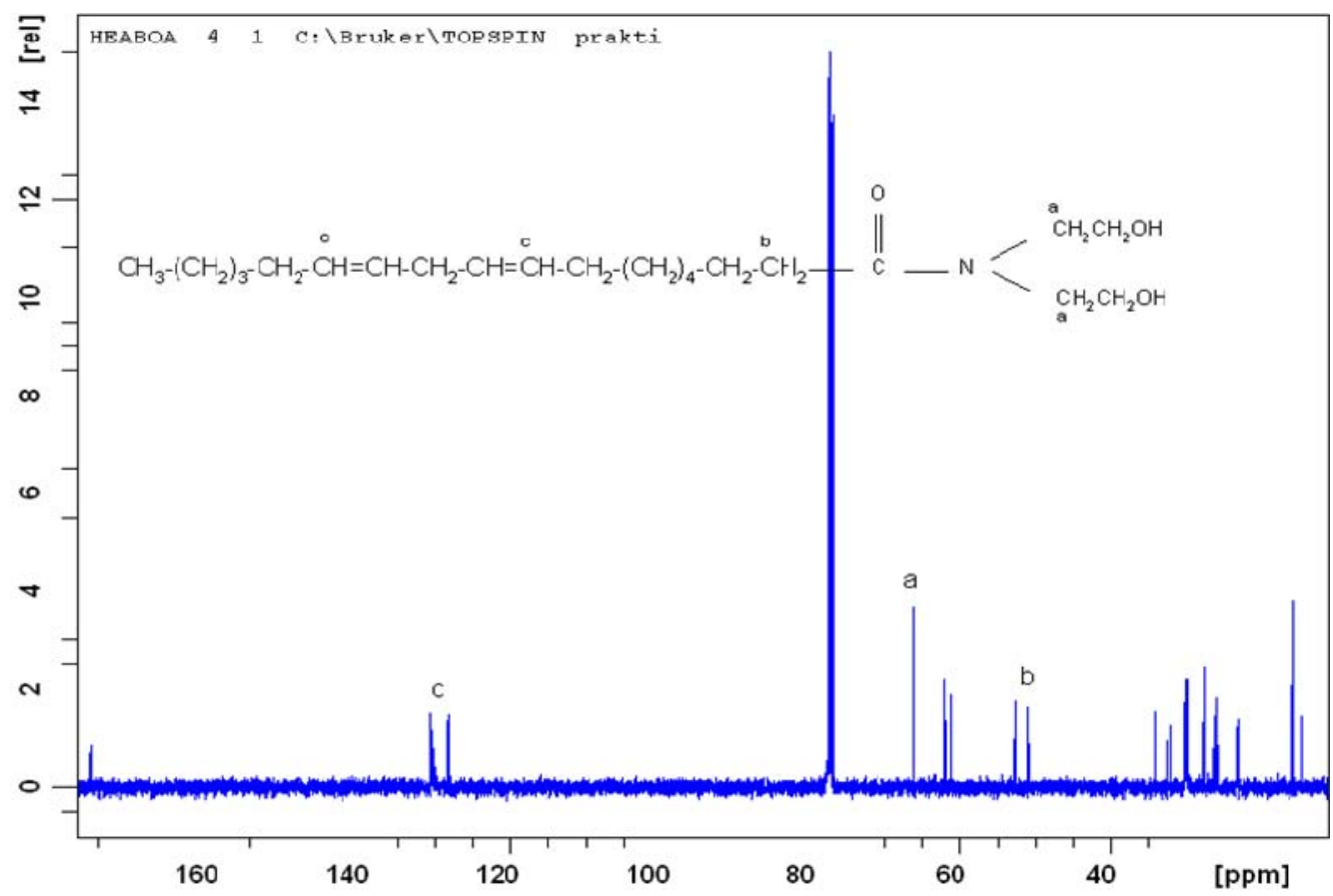

Fig 3: 13C NMR spectra of HEABOA 
Am. J. Sci. Ind. Res., 2011, 2(1): 78-88

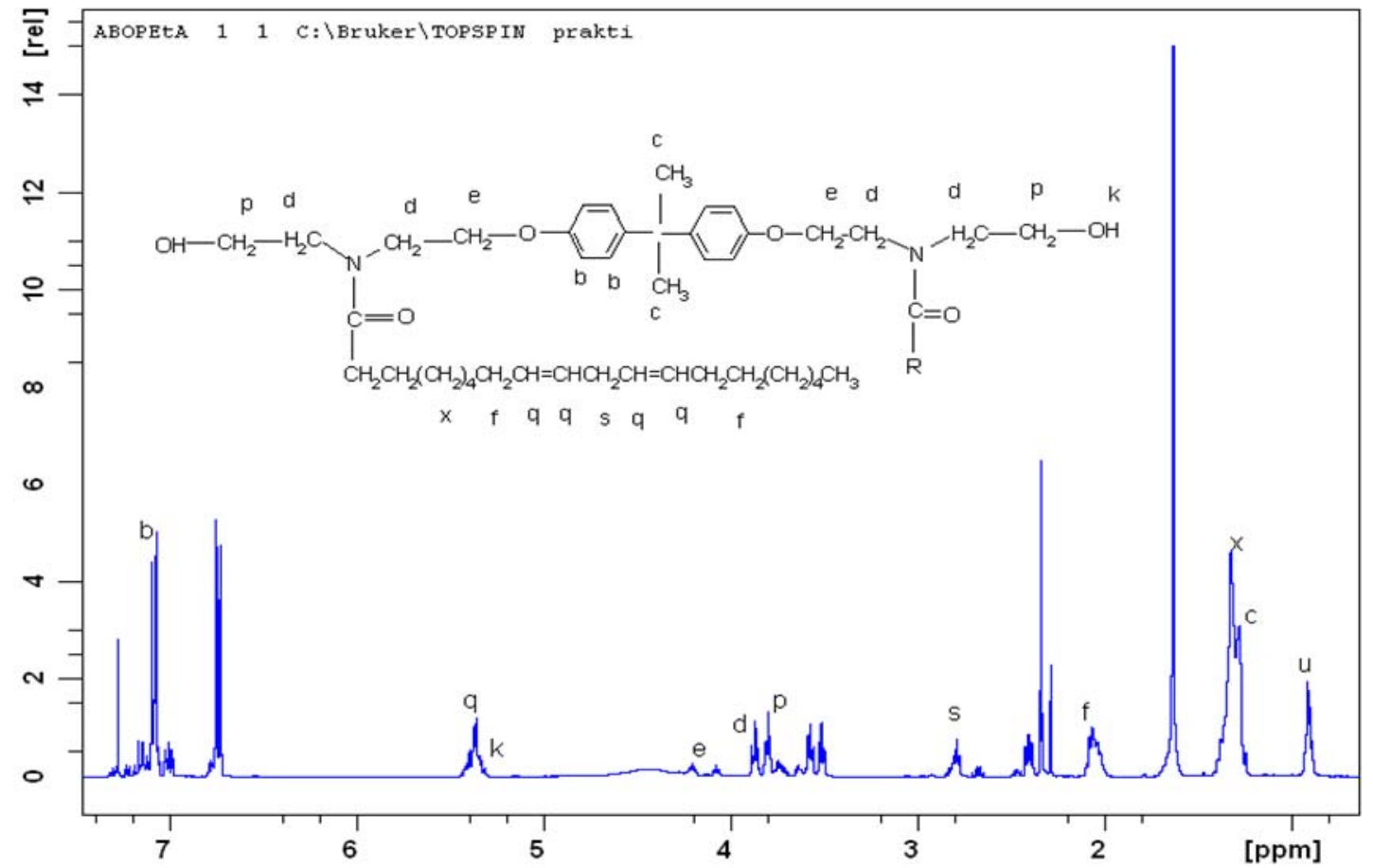

Fig 4: ${ }^{1} \mathrm{H}$ NMR spectra of ABOPEtA

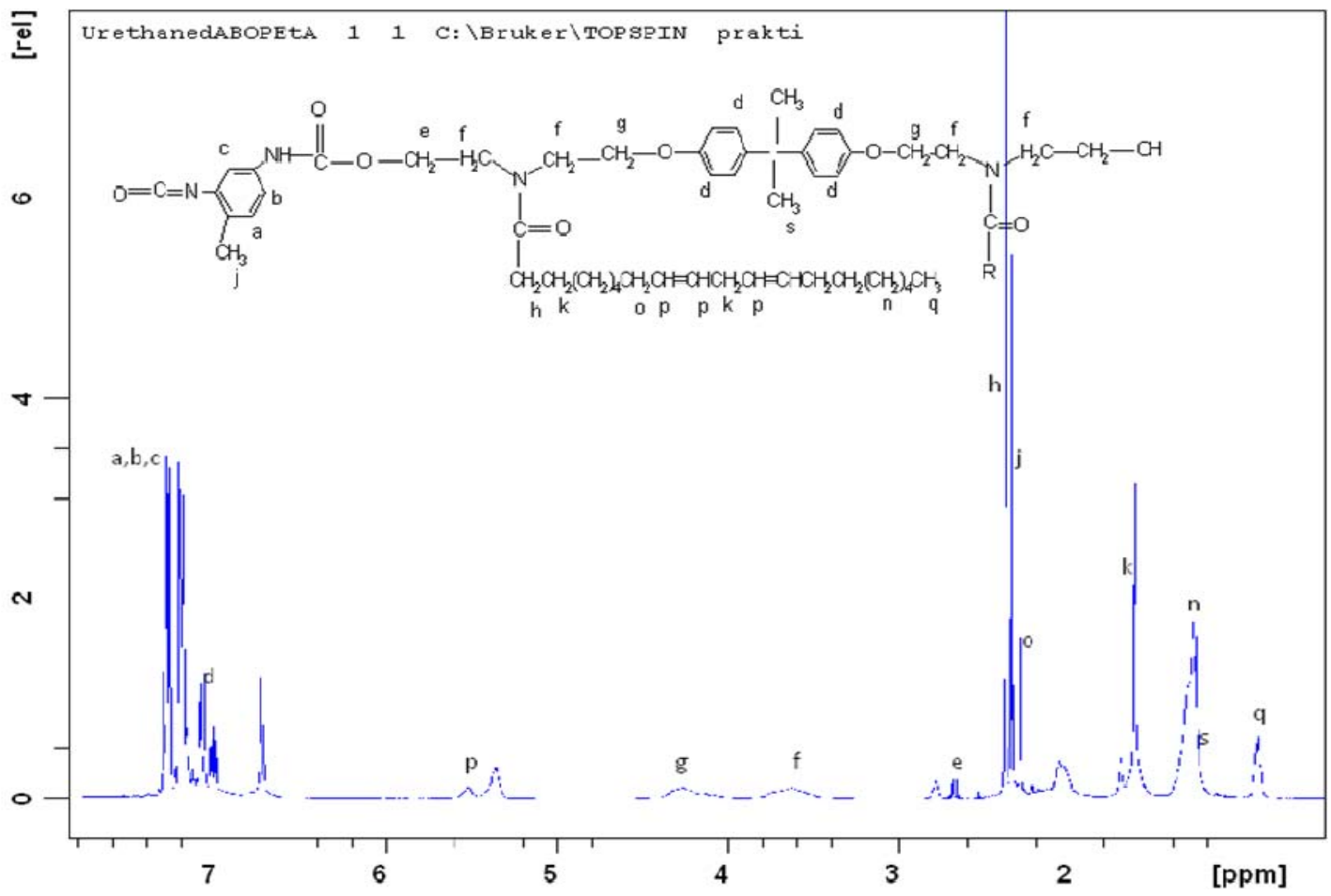

Fig 5: ${ }^{13} \mathrm{C}$ NMR of ABOPEtA 
Am. J. Sci. Ind. Res., 2011, 2(1): 78-88

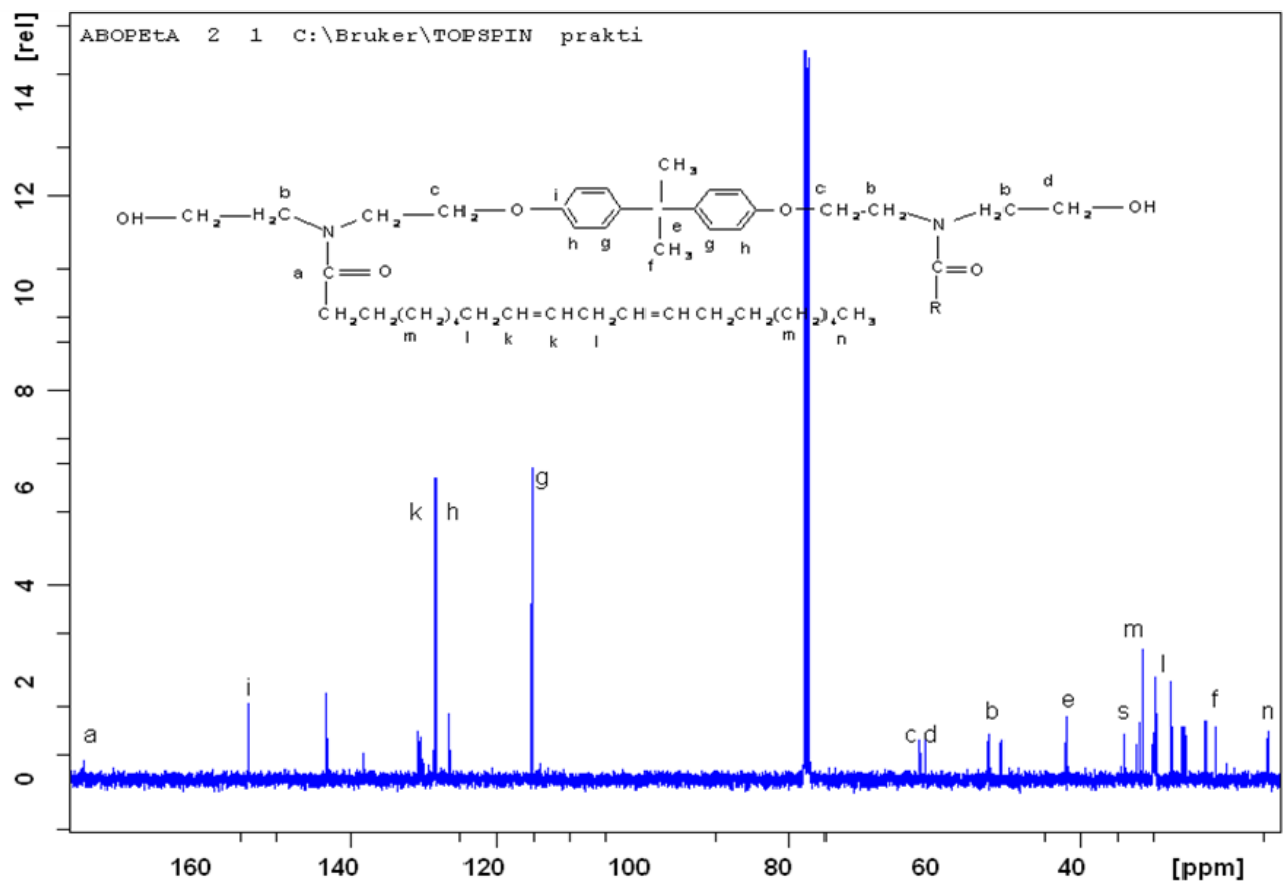

Fig 6: ${ }^{1} \mathrm{H}$ NMR spectra of UABOPEtA

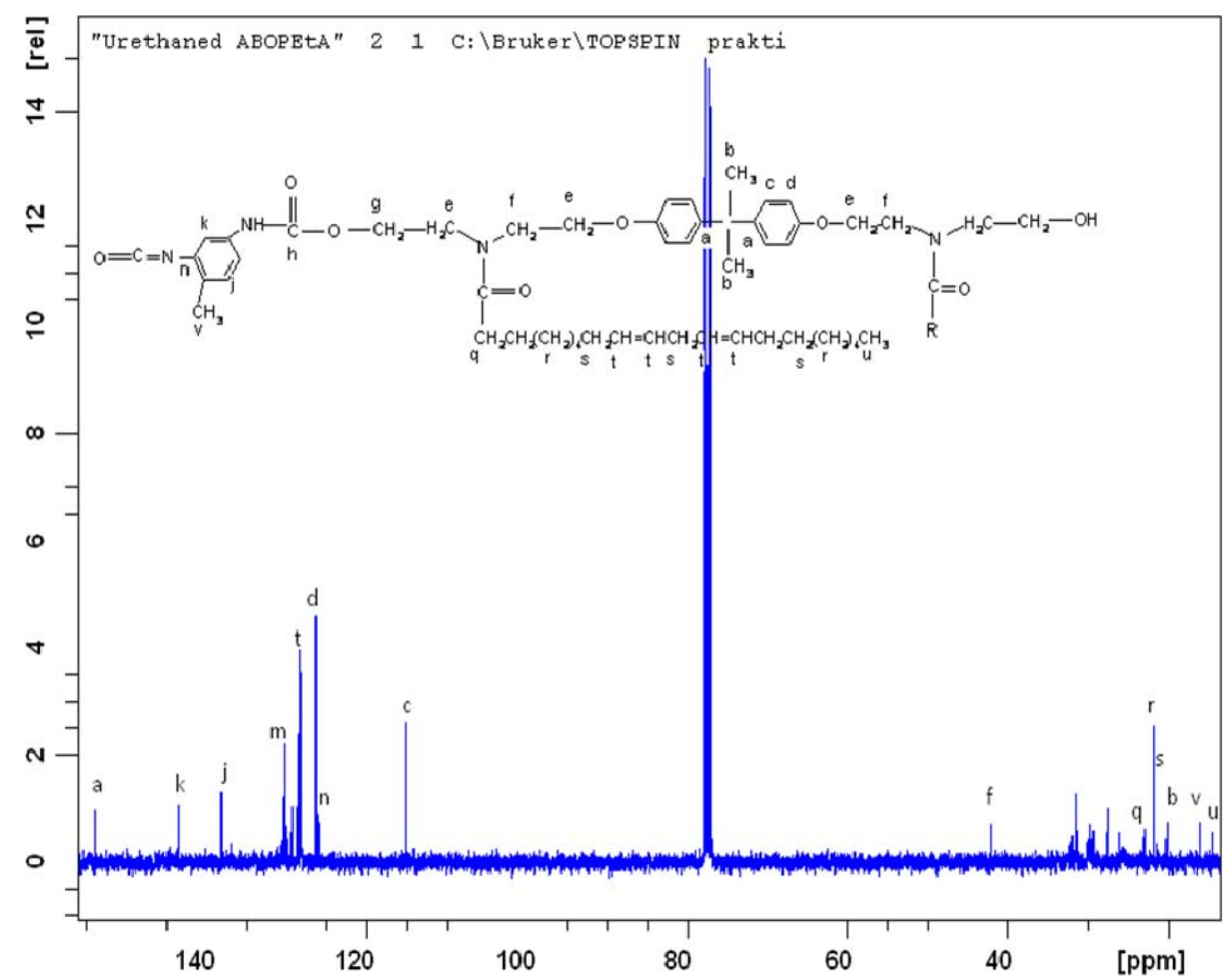

Fig 7: ${ }^{13} \mathrm{C}$ NMR of UABOPEtA 
Spectral Analysis of UABOPEtA: Reactions between ABOPEtA with TDI forming urethane modified polyetheramide [UABOPEtA] is suggested by reduction both in intensity and broadness of the band of residual hydroxyl group at $3322.75 \mathrm{~cm}^{-1}$ presented in Fig 1. The appearance of band at $1710 \mathrm{~cm}^{-1}$ is characteristic of carbonyl of urethane linkage while the aromatic band for TDI is at $743 \mathrm{~cm}^{-1}$.

The ${ }^{1} \mathrm{H}$ NMR (Fig 6) further confirms the structure as shown in scheme 3 with characteristic peaks of $-\mathrm{CH}_{2}$ attached to urethane linkage at $\delta 2.68 \mathrm{ppm}$ $2.67 \mathrm{ppm},-\mathrm{CH}_{3}$ of TDI at $\delta 2.29 \mathrm{ppm}$ while aromatic protons appeared at $\delta 7.28-7.26 \mathrm{ppm}$. The observed peak for $-\mathrm{NH}$ of urethane is at $\delta 7.3 \mathrm{ppm}$. The disappearance of peaks at $\delta 3.5-3.8 p p m$ corressponding to the $\mathrm{CH}_{2}$ attached to amide and hydroxyl is an evidence that during the reaction between free $-\mathrm{OH}$ group of ABOPEtA and $-\mathrm{NCO}$ groups of TDI, $-\mathrm{CH}_{2}$ were consumed and the reduction in peak $\delta=5.38-5.36 \mathrm{ppm}$ signified consumption of olefinic proton while residual $-\mathrm{OH}$ peak appears at $\delta 5.5 \mathrm{ppm}$.

Carbon 13-NMR (Fig 7) spectra reveals the appearance of $-\mathrm{CH}_{3}$ peaks for TDI at $\delta=22.9 \mathrm{ppm}$

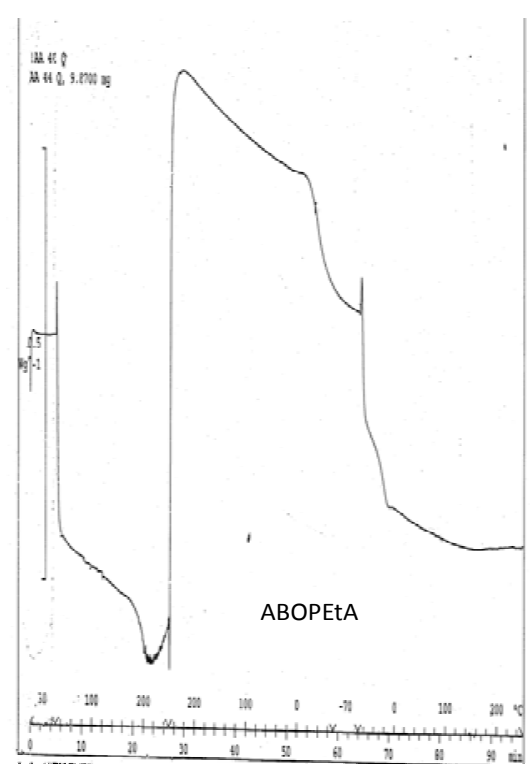

while that for internal $-\mathrm{CH}_{2}$ of fatty amine chain appears at $\delta 31.4$ - 27.6.ppm.

The $-\mathrm{CH}_{2}$ attached to double bond and to amide carbonyl occur at $\delta 26.0 p p m$ and $\delta 32.3-31.9 p p m$ respectively. Peak for quartenary carbon of bisphenol is still at $\delta 42.0 \mathrm{ppm}$ but dissapearance of peaks at $62.09-50.8 p p m$

Differential Scanning Calorimetric Analysis:The DSC thermograms of the ABOPEtA and UABOPEtA is shown in Fig 4. For ABOPEtA, curing starts at $210^{\circ} \mathrm{C}$ and ends at $250^{\circ} \mathrm{C}$. Thermosetting of the resin starts after this event. The broadness of the peak shows the non-homogeneity of the sample. For UABOPEtA, curing starts at around $160^{\circ} \mathrm{C}$ and extend to $180^{\circ} \mathrm{C}$. The presence of urethane linkages encourages curing at lower temperatures leading to configurational changes in the polymeric chains. Such enhancement of curing by urethane bonds has been earlier reported by Alam et.al (2004). Glass transition (Tg) of ABOPEtA was $-20.56^{\circ} \mathrm{C}$ while the $\mathrm{Tg}$ of UABOPEtA occurred at $18.66^{\circ} \mathrm{C}$. The increase in $\mathrm{Tg}$ on urethanation can be attributed to the stiffening due to the appended aromatic moieties of TDI and the intramolecular hydrogen bonding among the urethane groups.

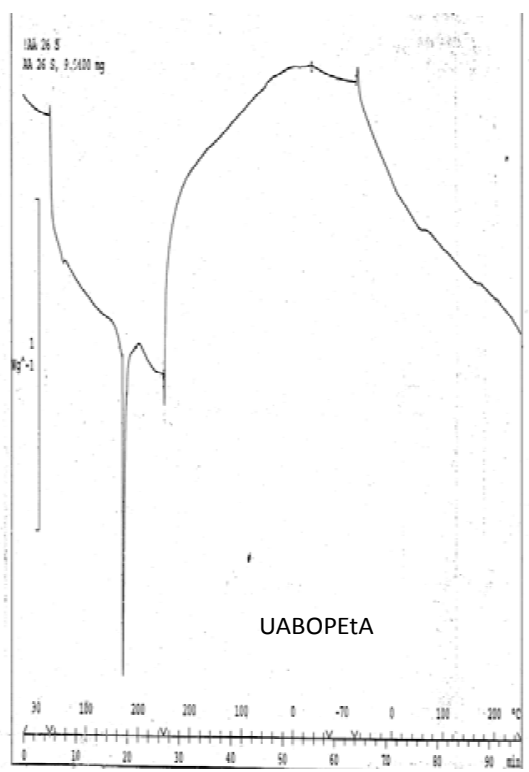

Fig 8 : DSC thermograms of ABOPEtA and UABOPEtA 


\section{Physicochemical characteristics}

Table 1 presenting the physicochemical characteristics reveals that a decrease in hydroxy value (HV) and iodine value (IV) in the order HEABOA, ABOPEtA, UABOPEtA-10, UABOPEtA-15, UABOPEtA-20, UABOPEtA-30. The sharp decrease in HV on going from HEABOA to ABOPEtA is due to the reaction of some hydroxyl moeities of HEABOA with Bisphenol-A to form ABOPEtA while the same decrease observed for IV may be related to the increase in molar mass of ABOPEtA compared with
HEABOA. Further slight decrease in HV observed with gradual loading of TDI may also be explained to be due to reaction of hydroxyl groups on the the ABOPEtA with the -NCO of TDI to form UABOPEtA. This reaction further leads to increase in molar mass of the polymer and this accounts for the further decrease in IV also observed on gradual loading of TDI. The increase in specific gravity and refractive index from HEABOA, ABOPEtA, UABOPEtA-10, UABOPEtA-15, UABOPEtA-20, UABOPEtA-30 correlates with increase in molar mass of the system in that order.

Table 1: Physico-Chemical characteristics of HEABOA, ABOPEtA and various UABOPEtA

\begin{tabular}{|l|c|c|c|c|}
\hline & $\begin{array}{l}\text { Hydroxyl value } \\
(\mathrm{mgKOH} / \mathrm{g})\end{array}$ & $\begin{array}{l}\text { lodine value } \\
(\mathrm{mg} \text { lodine/g) }\end{array}$ & $\begin{array}{l}\text { Specific gravity } \\
\left(\mathrm{g} / \mathrm{ml} 25^{\circ} \mathrm{C}\right)\end{array}$ & $\begin{array}{l}\text { Refractive Index } \\
\left(25^{\circ} \mathrm{C}\right)\end{array}$ \\
\hline ABO & 0.30 & 104.50 & 0.915 & 1.4725 \\
\hline HEABOA & 10.52 & 85.50 & 0.925 & 1.4850 \\
\hline ABOPEtA & 5.25 & 40.05 & 0.935 & 1.5225 \\
\hline UABOPEtA-10 & 4.05 & 35.24 & 0.938 & 1.5240 \\
\hline UABOPEtA-15 & 3.90 & 32.15 & 0.942 & 1.5245 \\
\hline UABOPEtA-20 & 3.35 & 28.26 & 0.948 & 1.5252 \\
\hline UABOPEtA-30 & 2.90 & 22.50 & 0.951 & 1.5275 \\
\hline
\end{tabular}

Coating Properties: The ABOPEtA and the urethaned modified samples were applied on $15 \mathrm{~cm} \mathrm{X}$ $15 \mathrm{~cm}$ steel panels and kept in vertical positions. The results presented in table 2 show that while the ABOPEtA were non-drying, the urethaned modified ABOPEtA were air drying and the drying time decreased with increase in TDI loading. While the UABOPEtA-10 took $1.5 \mathrm{~h}$ to become dry to touch and $12 \mathrm{~h}$ to hard dry, UABOPEtA-30 took onlz $30 \mathrm{~min}$ to surface dry and $1 \mathrm{~h}$ to hard dry.

The scratch hardness was estimated by estimating the pencil hardness of the films. The hardness was expressed in terms of the designation of the hardest pencil that failed to scratch the films. The results presented in table 2 also revealed that scratch hardness improved with increased loading of TDI.

Table 2 also revealed that the impact resistance $(1 \mathrm{~kg}$ load) and bend test (1/8 inch-mandrel) were passed by the UABOPEtA-10, UABOPEtA-15, UABOPEtA20 while the

UABOPEtA-30 failed. These properties may be correlated to the polar groups present in the samples. Outstanding flexibility (1/8 inch mandrel) is conferred by the polar urethane and ether linkages as well as the fatty amide chains. These also lead to good adhering coatings which have improved impact resistance. The $-\mathrm{NH}$ groups of urethane linkages form hydrogen bonds with the substrate and with carbonyl oxygen atoms of the poletheramide( ) leading to enhanced scratch hardness, impact resistance and flexibility behaiviour. However, UABOPEtA-30 failed these physico- chemical properties. At UABOPEtA-30, it is likely that the additional isocynate is liable to give too much cross linking, Also the presence of Bisphenol groups along with the aromatic ring of TDI (at 30wt of loading and above) introduce rigidity in the polymer resin leading to a deterioration of the above properties.

Chemical Resistance: The thinned solutions of the resins were applied on a $15 \mathrm{~cm} \times 15 \mathrm{~cm}$ glass panels and each set was immersed separately in distilled water, xylene, $2 \%$ solution of each of $\mathrm{HCl}$ and $\mathrm{NaOH}$ and $3.5 \%$ solution of $\mathrm{NaCl}$. The panels were taken out of the solutions at regular intervals of time, washed in fresh running water, dried for an hour and film examined for visible change. The results presented in table 3 indicate that urethanation of ABOPEtA led to greatly improved chemical resistance. 
Am. J. Sci. Ind. Res., 2011, 2(1): 78-88

Table 2: Physico-mechanical performance of ABOPEtA and various UABOPEtA

\begin{tabular}{|l|c|c|c|c|c|}
\hline & $\begin{array}{l}\text { Scratch hardness } \\
\text { (Pencil brand) }\end{array}$ & $\begin{array}{l}\text { Impact Resistance } \\
\text { (1Kg load) }\end{array}$ & $\begin{array}{l}\text { Surface Drying } \\
\text { Time } \\
\text { (hr) }\end{array}$ & $\begin{array}{l}\text { Hard Drying Time } \\
\text { (hr) }\end{array}$ & $\begin{array}{l}\text { Flexibility and } \\
\text { Adhesion } \\
(1 / 8 \text { inch mandrel) }\end{array}$ \\
\hline ABOPEtA & 6B & Fail & Non- Drying & Non-Drying & Fail \\
\hline UABOPEtA-10 & 4B & Pass & 1.5 & 12 & Pass \\
\hline UABOPEtA-15 & 2B & Pass & 1.0 & 6 & Pass \\
\hline UABOPEtA-20 & 2H & Pass & 0.5 & 4 & Pass \\
\hline UABOPEtA-30 & 3H & Fail & 0.5 & 1 & Pass \\
\hline
\end{tabular}

Table 3: Chemical resistance performance of ABOPEtA and various UABOPEtA

\begin{tabular}{|l|c|c|c|c|c|}
\hline & $\begin{array}{l}\text { Water } \\
\text { Resistance }\end{array}$ & Xylene Resistance & $\begin{array}{l}\text { Alkali Resistance } \\
(2 \% \mathrm{NaOH})\end{array}$ & $\begin{array}{l}\text { Acid Resistance } \\
(2 \% \mathrm{HCl})\end{array}$ & $\begin{array}{l}\text { Salt Resistance } \\
(3.5 \% \mathrm{NaCl})\end{array}$ \\
\hline ABOPEtA & $\mathrm{e}$ & $\mathrm{f}$ & $\mathrm{e}$ & $\mathrm{e}$ & $\mathrm{d}$ \\
\hline UABOPEtA-10 & $\mathrm{c}$ & $\mathrm{b}$ & $\mathrm{e}$ & $\mathrm{c}$ & $\mathrm{c}$ \\
\hline UABOPEtA-15 & $\mathrm{b}$ & $\mathrm{a}$ & $\mathrm{c}$ & $\mathrm{b}$ & $\mathrm{b}$ \\
\hline UABOPEtA-20 & $\mathrm{b}$ & $\mathrm{a}$ & $\mathrm{b}$ & $\mathrm{b}$ \\
\hline UABOPEtA-30 & $\mathrm{b}$ & $\mathrm{a}$ & $\mathrm{b}$ & $\mathrm{b}$ \\
\hline
\end{tabular}

a - not affected; b - slight loss of gloss; c - loss of gloss;

$\mathrm{d}$ - slight blistering; $\mathrm{e}$ - blistering; $\mathrm{f}$ - film completely removed

\section{CONCLUSION:}

A new urethaned modified polyetheramide resin was developed using Albizia benth oil, a sustainable resource. The resin was airdrying with improved scratch hardness and better flexibilty and showed better chemical resistance which may be attributed to the combination of properties of bisphenol-A, ether and urethane. The resin also cured at lower temperature. All these reveal the new resin as a good candidate for preparing ambient cured anticorrosive coating.

\section{ACKNOWLEDGEMENT:}

This work was funded by the International Foundation for Science (IFS) in conjuction with the Organisation for the Prohibition of Chemical Weapons (OPCW), Grant No F/4588-1 to Akintayo C.O. We also appreciate the provision of some facilities by Prof Thomas Ziegler of the Institute of Organische Chemie, Universitat Tubingen, Tubingen, Germany.

\section{REFERENCES}

Ahmad, S., Ashraf, S.M., Shamin, E., Naqvi, F., Yadav, S., Hasnat, A.(2002). Prog. Cryst. Growth 45: 83

Ahmad, S., Ashraf, S.M., Sharmin, E., Nazir M., Alam M. (2005). Prog Org. Coat. 52: 85

Ahmad,S., Ashraf, S.M., Naqvi, V., Yadav, S., Hasnat, A. (2001). J, Polymer. Mater. 18: 53

Ahmed, S., Ashraf, S.M., Naqvi, F., Yadav, S., Hasnat, A.(2003) Prog Org Coat. 47: 95
Aigbodion,A.I., Pillai, C.K.S., Bakare, I.O., Yahaya. L.E.(2001). Ind . J. Chem Tech. 8: 378

Akintayo, C.O., Adebowale, K.O. (2004). Prog. Org. Coat. 50: 133

Akintayo, C.O., Adebowale, K.O. (2004). Prog. Org. Coat. 50: 207

Alam, M., Sharmin E., Ashraf, S.M., Ahmad S. (2004). Prog Org Coat. 50: 224

DFG (1994). German Society for fat science, German Standard Methods for the Analysis of fats and other Lipids. Wissenschaftliche Verlagsgesellschaft $\mathrm{mbH}$, Stuttgart, Germany.

Indian Standard specification (IS). (1964). 101:38

Indian Standard specifications (IS). (1981).158: 8

LI, F., Hanson, M.V., Larock, R.C.(2001). Polymer 42: 1567

Li, F., Marks, D.W., Larock R. C., Otaigbe, J.U. (2000).Polymer 41: 7925

Shabeer, A., Garg, A., Sundararaman, S., Chandrashekhara, K., Flanigan, V., Kapila, S. (2005). J. Appl. Polym. Sci. 98: 1772

Wei,H.Y., Shi, W.F., Nie, K.M., Shen, X.F. (2002). Polymer 43: 1969 